\title{
BRUNO DE MENEZES E O MODERNISMO NO PARÁ
}

\author{
Terezinha de Jesus Dias Pacheco*
}

RESUMO:

A necessidade de inserir a literatura local paraense no contexto modernista nacional levou Bruno de Menezes a promover vārios debates sobre a renovação literāria no Parā. Sua inquietação contagiou alguns intelectuais nativos que produziram obras que dialogaram com a corrente modernista brasileira. Nessa esteira, os modernistas paulistas vieram apenas trocar experiências literárias na Amazônia.

PALAVRAS-CHAVE: Bruno de Menezes, modernismo, Parā, renovação.

"...Por iniciativa do festejado escritor, Sr. Graça Aranha, da Academia Brasileira de Letras, haverá em São Paulo uma 'Semana de Arte Moderna', em que tomarão parte os artistas que, em nosso meio, representam as mais modernas correntes artísticas". Esclarecia, também, que para esse fim 0 Teatro Municipal ficaria aberto durante a semana de 11 a 18 de fevereiro, instalando-se nele uma interessante exposição. (Brito, 1986: 17)

Oficialmente, foi dessa maneira que o Modernismo instalou-se no Brasil, mais especificamente, em São Paulo. Esse movimento literário ansiava por mudanças mais ou menos radicais, que pudessem dar à Literatura Brasileira feições essencialmente nacionalistas. Menotti del Picchia, participante da Semana de Arte Moderna, esclarece, em seu discurso como orador oficial da segunda noite, o que se pensava sobre 0 Modernismo:

A nossa estética é de reação. Como tal, é guerreira. 0 termo futurista, com que erradamente a etiquetaram, aceitamo-10 porque era um cartel de desafio. Na geleira de mármore de Carrara do Parnasianismo dominante, a ponta agressiva dessa proa verbal estilhaçava como um aríete. Não somos, nem nunca fomos "futuristas". Eu, pessoalmente, abomino o dogmatismo e a liturgia da escola de Marinetti. Seu chefe é para nós um percursor iluminado, que veneramos como um general da grande batalha da Reforma, que alarga o seu 'front' em todo o mundo. No Brasil não há, porém, razão lógica e social para o futurismo ortodoxo, porque o prestígio do seu passado não é de molde a tolher a

|* Mestre em Letras: Estudos Literários (Área de concentração: Teoria da Literatura), 2001. 


\section{EM TESE}

Belo Horizonte, v. 6, p. I-253, ago. 2003

liberdade da sua maneira de ser futura. Demais, ao nosso individualismo estético repugna a jaula de uma escola. Procuramos, cada um, atuar de acordo com nosso temperamento, dentro da mais arrojada sinceridade.

(...) Queremos luz, ar, ventiladores, aeroplanos, reivindicações obreiras, idealismos, motores, chaminés de fábricas, sangue, velocidade, sonho, na nossa Arte. E que o ruído de um automóvel, nos trilhos de dois versos, espante da poesia o último deus homérico, que ficou, anacronicamente, a dormir e a sonhar, na era do jazz-band e do cinema, com a flauta dos pastores da Arcádia e os seios divinos de Helena! (Brito, 1986: 18)

Menotti del Picchia, usando uma linguagem rebelde, anuncia o sentimento de mudança e reflexos que a nova estética deveria assumir e expressar. Por esses motivos, para a historiografia da Literatura Brasileira, o Modernismo começa no Brasil a partir da Semana de 1922. Entretanto, no Pará, essas idéias sobre rompimento com estéticas anteriores chegaram antes de 1922.

Joaquim Inojosa, poeta e escritor pernambucano, numa "palestra realizada em Belém do Pará, em 26 de maio de 1972, por ocasião da Festa do Paraense do Livro" (Inojosa, 1994: 109) sobre o Modernismo no Brasil, proferiu as seguintes palavras:

Estava-se, contudo, em 1921, quando um sentimento parecia predominar nos espíritos dos jovens: o do nacionalismo. Vinte ou mais dentre eles, numa espécie de academia ao ar livre, era a quantos [sic] por vezes atingiam aquelas tertúlias. Delas participavam Abgar, De Campos Ribeiro, Bruno de Menezes, Raul Bopp, Clóvis de Gusmão, Santana Marques, Nunes Pereira, Paulo 01 iveira, Severino Silva. Cenáculo de "fatos correntes, fofocas e anedotas", comentaria Bopp, em que também se "agitavam opiniões, notadamente no campo literário", mas de "intelectualismo sem direção" e de "efeitos estéreis". (Inojosa, 1994: 111)

Se compararmos o texto de Joaquim Inojosa ao de Menotti del Picchia, perceberemos que os anseios de renovação são os mesmos: queriam se livrar do dogmatismo intelectual que ditava as regras e conceitos literários. Porém, a maneira de conduzir a independência é bastante diferente. Enquanto os paulistas precisaram do escritor Graça Aranha, que pertencia à Academia Brasileira, para fazer a abertura da Semana de Arte Moderna e de um orador oficial como Menotti del Picchia, para introduzir e legitimar as suas idéias, os paraenses preferiram a academia ao ar livre, não só tentando mostrar que não é buscando o atrelamento a uma instituição legitimadora que se operam mudanças, mas procurando maneiras de rompimento que atingissem a raiz do problema. 
Bruno de Menezes participava dessa academia ao ar livre, que recebia diferentes epítetos, conforme a ocasião. No momento em que se reuniam no Ver-o-Peso, era a Academia Peixe-Frito. Eram encontros regados a aperitivos e, como tira-gosto, peixe frito. Em outras situações diziam ser Vândalos do Apocalipse por talvez estarem discutindo e anunciando a poética dos novos tempos. Tempos depois organizaram a Associação dos Novos para divulgar as novas idéias.

Ligado ainda a uma estética parnasiana, mas imbuído de uma necessidade de mudança, Bruno de Menezes expõe em um soneto suas impressões sobre o momento que está vivendo:

Arte Nova

Eu quero um'Arte original... Daí esta insatisfação na minha Musa! Ânsias de ineditismos que eu não vi e o vulgo material inda não usa!

E a Idéia é ignota... A Perfeição em si, tem segredos de morte e alma reclusa... Sendo a glória espinhosa, - eu me feri... justo e, pois, que este sonho arda e relusa!...

Toda a volúpia estética do Poeta que eu sou, - para a Poesia que mim sinto, provém desse Querer em linha reta!

Gloriosa um'Arte que os Ideais renova!

- Razão da causa por que eu me requinto

na extravagância de uma imagem nova! (Menezes, 1993: 454)

Embora Bruno de Menezes não tivesse inserido no Modernismo, ia paulatinamente expressando o desejo de conseguir construir uma nova poética. No início do poema, ele rejeita a cópia, anseia por uma arte que seja inédita. Ainda não sabe como realizar o seu anseio, mas busca uma imagem nova.

"Arte Nova" é um metapoema, no qual o autor tenta questionar o fazer poético. Para ele, a criação poética é um árduo trabalho, é tirar a palavra de um encarceramento semântico. Re-significar as palavras é uma tarefa que se impõe: rever conceitos e formas literárias é uma necessidade íntima do poeta. Ele, embora sem direção, já anuncia a sua nova concepção de poesia. Caminha para a liberdade de poder expressar o que estiver de acordo com sua concepção poética. 0 sujeito desse 


\section{EMTESE}

Belo Horizonte, v. 6, p. I-253, ago. 2003

poema repudia todos os postulados canônicos da poesia, até então instituídos. Começa a querer destruir as amarras que aprisionam as palavras em regras. Através de uma forma poética canonizada - o soneto - Bruno de Menezes tenta experimentar 0 novo na literatura.

Para trabalhar melhor as renovações necessárias na literatura paraense, esse grupo organizou uma revista denominada Belém Nova:

Belém Nova, revista lançada a 15 de setembro de 1923 e que marcou época, apontando novos rumos à literatura planetária, era de idealização de Bruno e sob sua direção, fez eco em nossa terra do movimento literário de vanguarda que empolgou 0 Brasil; eram seus companheiros de redação Edgar Franco, Alfredo de Souza e Manoel Malhado. (Rocha, 1996: 42-43)

Deixando de lado a adjetivação que dá ao texto de Alonso Rocha uma dimensão hiperbólica da repercussão da Belém Nova, é possível perceber que essa revista foi um dos recursos usados para a divulgação do Modernismo no Pará. Sobre ela, Bruno de Menezes faz o seguinte comentário:

Àquele tempo a nossa chamada "nova geração" organizou o seu reduto de idéias, literariamente avançadas, nesse quinzenário, no qual, apesar das influências e do entusiasmo pela Arte Nova da maioria de seus fundadores, colaboravam homens de letras de todos os credos estéticos. (Menezes, 1996: 57)

Apesar dos esforços pela renovação literária, Bruno de Menezes, nesse texto, esclarece que outras correntes estéticas coexistiam nos escritos da Belém Nova, fazendo desse quinzenário um lugar de debate literário, não se anulando o que existia, mas procurando estabelecer um diálogo com vistas a modificações impostas pelo tempo.

Afonso Rocha afirma ainda que Bruno de Menezes foi o idealizador e diretor da referida revista e que tinha companheiros de redação. Bruno de Menezes não se coloca como idealizador, mas como um dos fundadores da Belém Nova, que contava com a colaboração dos demais fundadores. Embora tenha sido um dos diretores desse quinzenário, procura passar a idéia de que a Belém Nova é obra da "nova geração".

Embora possamos considerar que a Belém Nova é um dos sinalizadores do início do Modernismo no Pará, há quem afirme peremptoriamente que o ingresso do Pará no Modernismo se deve a este ou a aquele intelectual. A partir de agora iremos confrontar alguns textos em que são feitas tais afirmações. 
Joaquim Inojosa, sobre a origem do Modernismo paraense, diz o seguinte:

Chegaram-1hes notícias dos arreganhos paulistas através de Pernambuco, e não certamente pelo discurso de Graça Aranha, pois ali, de 1922, começara 0 movimento em tons iconoclastas. Surpresa alguma, aliás, deve causar esta afirmação sabido que os ecos da Semana de Arte Moderna atingiram ao Recife no mesmo ano de 1922, antecipando-se ao Rio de Janeiro no que iria representar de luta e violência, a pregação modernista.

Embora mantivéssemos correspondência epistolar e permuta de livros, em 1924, quis Bruno de Menezes que um intelectual pernambucano, aqui de passagem, relatasse para a sua revista o que de verdade se desenrolava na Veneza Americana, em torno da renovação literária. E Abgar Soriano de 01 iveira, na "Belém Nova", de maio daquele ano, prestou um depoimento de valor histórico na conceituação das influências renovadores partidas do Recife para alcançarem outras capitais brasileiras. (Inojosa, 1994: 113-114)

Para Aníbal Machado, a história é outra, pois enquanto os paulistas sabiam "o que não queriam", os intelectuais do Rio de Janeiro, de Belém e do resto do Brasil apenas "ansiavam". Afirma ele ainda que

movimento de maior envergadura surgiu, certamente influenciado pelo movimento dominante no Sul e já praticamente vitorioso. Intelectuais do Pará tomaram a atitude revolucionária nas letras chefiada por Graça Aranha. (Inojosa, 1994: 112-113)

Alonso Rocha escolhe a sua versão e declara:

Mário de Andrade - o papa do Modernismo - Raul Bopp, Tasso da Silveira, Lucilo Zender, Paulo de 01 iveira, Farias Gama, De Campos Ribeiro, Wenceslau Costa, Jacques Flôres, José Carvalho, Assis Garrido, Jonathas Baptista, Joaquim Inojosa e muitos outros aplaudiram o novo trabalho do poeta paraense que se projetava no cenário intelectual brasileiro, como um dos renovadores da poesia nacional, aderindo ao movimento liderado por Graça Aranha. (Rocha, 1996: 43)

Leandro Tocantins, escritor amazonense pensa diferente:

A revista de Mário de Andrade estimulou os movimentos modernistas de Belém e Manaus. Principalmente de Manaus, que na Amazônia foi uma espécie de Meca do Modernismo inspirado no eixo Rio-São Paulo. 0 que se pode julgar é que talvez em Belém faltaram ímpeto, instrumentos humanos e materiais decisivos a desencadear o movimento que em Manaus ganharia maior expressão. (Inojosa, 1994: 129)

Georgenor Franco, poeta paraense, por sua vez, em palestra proferida sobre a renovação literária no Pará, denominada "Ā margem do movimento modernista", 


\section{EM TESE}

Belo Horizonte, v. 6, p. I-253, ago. 2003

expõe a sua opinião baseando-se em datas de formação de grupos que discutiam os novos rumos da literatura e também de publicações literárias que já anunciavam nas suas temáticas a novidade:

Pelo visto, verifica-se que o movimento modernista, antes de evoluir e revolucionar a literatura no Sul do país, já fervilhava no Pará. Isso prova que 0 nosso estado nunca esteve atrelado a carro de bois. (Inojosa, 1994: 112)

Temos aqui quatro possibilidades de filiação do Modernismo Paraense. Aníbal Machado atribui a Graça Aranha a paternidade do movimento modernista paraense, com que concorda passivamente Alonso Rocha, que, como biógrafo de Bruno de Menezes, deveria ter sido mais cuidadoso quando afirma o atrelamento de Bruno de Menezes a Graça Aranha, já que aquele, antes da Semana de Arte Moderna, expressava em seu poema, "Arte Nova", que queria uma arte original, inédita e não a cópia. Entretanto, Leandro Tocantins legou o anúncio da boa nova modernista na região amazônica a Mário de Andrade, que esteve no Norte do Brasil em 1927, quando a nova geração paraense já tinha formado o modelo modernista em Belém do Pará. Lendo o poema "Chapeleirinhas", de Bruno de Menezes, que foi publicado em 1924 no seu livro de poemas Bailado Lunar, sentimos que, já em 1924, sua escrita já registra sinais do estilo modernista.

\section{Chapeleirinhas}

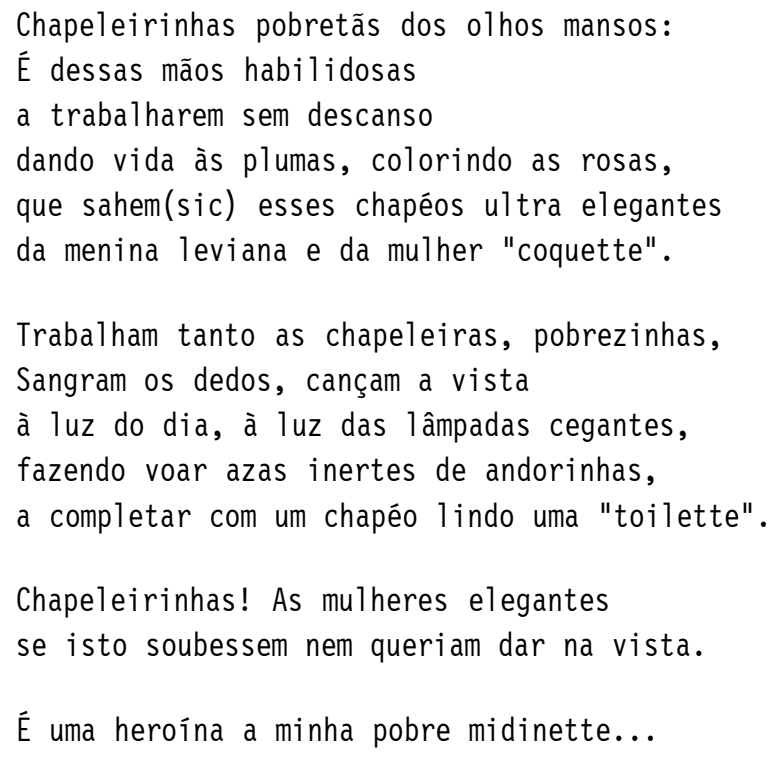

Visualizamos neste poema que Bruno de Menezes se utiliza de versos livres, embora ainda procure rimá-los. Utiliza um português um pouco rebuscado, mas 
já insere no poema termos franceses. A temática do poema mostra um paradoxo social vivido pelo mundo feminino. Mulheres pobres, trabalhadeiras, em oposição às mulheres ricas, que naturalmente não têm ocupações profissionais ou, se as têm, praticam ocupações mais leves, e mulheres que ganham a vida vendendo a sua beleza. Mostra, dessa forma, que a sociedade está dividida em classes e que uma classe tem mais privilégios que outra.

Inserimos o referido poema e fizemos um comentário para dialogar com 0 texto de Leandro Tocantins e para constatar o quanto ele era desinformado, julgando que em "Belém faltaram ímpetos, instrumentos humanos e materiais decididos a desencadear o movimento que em Manaus, só em 1927, com Mário de Andrade, ganharia mais expressão".

Para Joaquim Inojosa, que era pernambucano, o Modernismo no Pará só começa quando os pernambucanos, que foram iniciados no Modernismo por obra e graça dos paulistas, fizeram contatos com os paraenses. Isso aconteceu no ano de 1924. Questionamos essa afirmativa de Joaquim Inojosa pelo mesmo motivo que questionamos Leandro Tocantins. 1924 é um momento em que o Modernismo no Pará não é mais novidade. As produções literárias do ano mostram sinais marcantes de adesão ao movimento.

Até aqui fica patente que, seja por intermédio de Graça Aranha, de Mário de Andrade ou de Joaquim Inojosa, o Modernismo chegou ao Pará via Semana de Arte Moderna. No entanto, Georgenor Franco se contrapôs a todas essas versões. Quando diz "que o nosso Estado nunca esteve atrelado a carro de bois", não está negando os diálogos e os intercâmbios culturais estreitados entre o sul e o norte. Tampouco está negando o mérito dos paulistas na organização da Semana de Arte Moderna, ou a contribuição de Raul Bopp, Mário de Andrade, Joaquim Inojosa e outros. Pensamos que Georgenor Franco tentou esclarecer que não foi só depois da Semana de Arte Moderna que o Pará veio a conhecer o Modernismo. No Pará e na Amazônia, de um modo geral, assim como em São Paulo, os intelectuais que estavam à margem do cânone literário começaram a se reunir, formar grupos, debater e partir para operar mudanças não só no campo literário, mas também no campo político, econômico e social. 0 que Georgenor Franco talvez queira explicar é que não estávamos de braços cruzados esperando que São Paulo enviasse a nova moda literária. 


\title{
EMTESE
}

Belo Horizonte, v. 6, p. I-253, ago. 2003

Dialogando com a França e a Europa e, depois, com os paulistas, pernambucanos, mineiros, os intelectuais paraenses que pertenciam ao grupo de Bruno de Menezes foram aos poucos assimilando a estética modernista. Assim como a nova geração paraense procurou estabelecer intercâmbio com Joaquim Inojosa, Anibal Machado, Ascenso Ferreira, Câmara Cascudo e outros, Mário de Andrade e Raul Bopp também vieram até a Amazônia trocar experiências literárias e não anunciar o Modernismo. Os paulistas não lideraram o Modernismo no Pará, mas deram significativa contribuição para a consolidação desse movimento no Norte do Brasil.

ABSTRACT :

The need to insert the literature produced in Para in the national modernist context led Bruno de Menezes to promote several debates about the literary renewal in the state. His concern contaminated some local intellectuals, who created works that participated in a dialogue with the Brazilian modernist mainstream. The modernist writers from São Paulo visited the northern states in order to share their literary experience with the local modernists.

KEY WORDS: Bruno de Menezes, modernism, Parā, renewal.

\author{
REFERÊNCIAS BIBLIOGRÁFICAS
}

BRITO, Mário da Silva. A revolução modernista. In: Coutinho, Afrânio (Org.). A literatura no Brasil. Niterói: EDUFF, 1986.

IN0J0SA, Joaquim. Modernismo no Pará. In: Bruno de Menezes ou a sutileza de transição: ensaios. Belém: CEJUP, Universidade Federal do Pará, 1994.

MENEZES, Bento Bruno Costa de. Poesia. Belém: CEJUP, 1993. V.I. p. $57,1996$.

Algumas palavras. Asas da Palavra, Belém, UNAMA, ROCHA, Alonso. Bruno de Menezes. Asas da Palavra, Belém, UNAMA, 1996. 